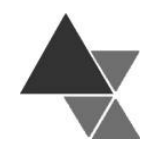

\title{
Quimiometria na classificação de leite cru refrigerado
}

\author{
Calionara Waleska Barbosa de Melo ${ }^{1}$, Igor Henrique de Lima Costa ${ }^{2}$, Gessica da Silva Macedo ${ }^{3}$ e \\ Roberta Barbosa de Meneses ${ }^{4}$
}

Objetivou-se avaliar as correlações entre os parâmetros de qualidade do leite cru refrigerado produzido em diferentes unidades produtoras através da análise de componentes principais (PCA). Foram consideradas as seguintes variáveis: acidez, crioscopia, densidade, teor de gordura, extrato seco total (EST), extrato seco desengordurado (ESD), $\mathrm{pH}$, contagem de células somáticas (CCS), contagem de bactérias totais (CBT) e teste de redução do azul de metileno (TRAM). Foi observado que as amostras se agruparam em cinco diferentes grupos: (I) não teve influência de nenhum vetor, (II) correlacionados com os parâmetros de CCS e CBT, possivelmente por apresentarem maiores contagens, sinalizando que possuem padrão de qualidade inferior em comparação com as demais amostras, o grupo (III) sofreu maior influência dos parâmetros de ESD, acidez, densidade e TRAM, enquanto o grupo (IV) foi discriminado majoritariamente pelos vetores de EST e gordura, indicando que as amostras exibem maior teor desses parâmetros e são oriundas de leite de boa qualidade, o grupo (V) foi caracterizado por uma correlação negativa com os vetores de EST, gordura, crioscopia e pH, evidenciando que essas amostras possuem um padrão de qualidade inferior. A partir da análise de PCA, as amostras foram agrupadas de acordo com a similaridade, permitindo constatar que os vetores que mais contribuíram para a discriminação das diferentes amostras de leite foram os valores de CCS e CBT.

Palavras-chave: Qualidade do leite; Análise de Componentes Principais; Parâmetros físico-químicos

\section{Chemiometry in the classification of chilled raw milk}

The objective was to evaluate the correlations between the quality parameters of chilled raw milk from different producing units through the principal components analisys (PCA). The following variables were considered: acidity, cryoscopy, density, fat content, total dry extract (TDE), defatted dry extract (DDE), pH, somatic cell count (SCC), total bacteria count (TBC) and methylene blue reduction test (MBRT). It was observed that the samples were grouped into five different groups: (I) had no influence from any vector, (II) correlated with the SCC and TBC parameters, possibly because they have higher counts, signaling that they have a lower quality standard compared to the other samples, group (III) was more influenced by the DDE, acidity, density and MBR parameters, while group (IV) was mainly discriminated by the TDE and fat vectors, indicating that the samples exhibit a higher content of these parameters and are produced from good quality milk, group (V) was characterized by a negative correlation with the vectors of TDE, fat, cryoscopy and $\mathrm{pH}$, showing that these samples have a lower quality standard. From the PCA analysis, the samples were grouped according to similarity, showing that the vectors that most contributed to the discrimination of different milk samples were the SCC and TBC values.

${ }^{1}$ Departamento de Gestão e Tecnologia Agroindustrial, Centro de Ciências Humanas Sociais e Agrárias, Universidade Federal da Paraíba, Brasil. Endereço para correspondência: Rua João Pessoa, S/N, Bananeiras, Paraíba, Brasil. CEP: 58220-000. Telefone: (83) 99632-0231. E-mail: kalionaramelo@hotmail.com

2 Departamento de Engenharia de Alimentos, Centro de Tecnologia, Universidade Federal da Paraíba, Brasil. ID ORCID: https://orcid.org/0000-0001-9766-1435

${ }^{3}$ Departamento de Gestão e Tecnologia Agroindustrial, Centro de Ciências Humanas Sociais e Agrárias, Universidade Federal da Paraíba, Brasil. ID ORCID: https://orcid.org/0000-00033241-6396

4 Professor Doutor em Ciência de Alimentos, Departamento de Gestão Agropecuária, Instituto Federal de Alagoas, Brasil. ID ORCID: https://orcid.org/0000-0002-8155-371X 
Keywords: Milk quality; Principal Component Analysis; Physico-chemical parameters.

Submetido em: 30/10/2020

Aceito em: 22/02/2021

\section{INTRODUÇÃO}

O leite é uma importante matéria-prima para a indústria de produtos lácteos e apresenta uma composição química complexa, constituída majoritariamente por água, cerca de $86 \%$, sólidos totais, gordura, proteínas, lactose, minerais e em menores teores, as vitaminas, bactérias, leucócitos e células mamárias secretoras ${ }^{[1}$. O conhecimento da composição química do leite é essencial para a determinação da qualidade microbiológica, pois define diversas propriedades sensoriais e industriais. Os parâmetros de qualidade são cada vez mais utilizados para detecção de falhas nas práticas de manejo, servindo como referência na valorização da matéria-prima ${ }^{[2]}$.

A legislação brasileira estabelece que o leite cru destinado ao consumo humano deve ser obtido a partir da ordenha completa, ininterrupta e higiênica, de vacas sadias, descansadas e bem alimentadas ${ }^{[3]}$. E de acordo com a Instrução Normativa no 76 , o leite cru refrigerado é uma matéria-prima de origem animal produzido em propriedades rurais, refrigerado e encaminhado aos estabelecimentos, sob o serviço de inspeção oficial, de leite e derivados. Portanto, estas condições implicam que esses estabelecimentos devem receber uma matéria-prima isenta de sujidades ou qualquer corpo estranho que comprometa sua qualidade durante o processamento e consumo ${ }^{[4]}$.

É bem relatado na literatura, a recepção do leite cru refrigerado com qualidade comprometida nas plataformas da indústria de laticínios; esta má qualidade pode estar relacionada as condições de manejo, nutricional, genética e principalmente atribuído a fatores higiênicos e fraudulentos que comprometem a integridade do leite ${ }^{[5,6]}$. Queiroz et al.[7] observaram diferenças na qualidade do leite cru refrigerado de trinta unidades produtoras (escolhidas aleatoriamente e sem predefinição do tipo de ordenha) em função das condições climáticas, no entanto os principais problemas relatados foram relacionados com a falta de higiene na obtenção e processamento da matéria-prima. Além disso, Gonçalves et al. destacam a importância da manutenção do estado sanitário do rebanho e das condições de armazenamento do leite para garantir e assegurar a qualidade.

Leite et al. [9] reforçam a importância de orientar e incentivar os produtores para implementação de Boas Práticas Agropecuárias (BPA) na produção de leite. É observado que há vários fatores envolvidos que impactam na composição química e microbiológica e consequentemente influenciam na qualidade do leite cru refrigerado. Nesse sentido há ferramentas estatísticas que podem auxiliar na interpretação do volume de dados e variáveis que podem estar relacionadas e que influenciam negativamente nesses parâmetros. Dentre essas ferramentas, os métodos quimiométricos, podem ser efetivos para essa finalidade, como exemplo de Strani et al.[10] que avaliaram a influência da temperatura, teor de gordura e $\mathrm{pH}$ no processo de coagulação do leite e conseguiram identificar uma variação no teor de gordura em função da origem de cada amostra que foi avaliada. Vale ressaltar que esses métodos podem ser considerados como ferramentas valiosas para o controle de qualidade e assim desempenhar importante papel na triagem de matéria-prima, como é o caso do leite cru refrigerado.

A quimiometria é uma subárea da química que manipula dados, de forma otimizada, resultantes de análises multivariadas através de ferramentas matemáticas, estatísticas e computacionais com a finalidade de promover uma melhor interpretação dos dados.[11] Várias técnicas estatísticas são bem estabelecidas na literatura e empregadas na indústria de alimentos, mas dentre elas uma alternativa promissora para correlação e classificação de dados é utilizar algoritmos que permitem verificar a distância direta entre objetos/componentes. Isto é, na projeção de dados em espaços de menor dimensão que é o caso da Análise de Componentes Principais (PCA) que permite verificar semelhanças entre amostras quando há similaridade ou disparidade química entre elas ${ }^{[12,13]}$. 
Desse modo, leite cru refrigerado com a qualidade comprometida, interfere negativamente na produção de produtos lácteos e levando em consideração a constante preocupação por parte dos produtores locais, esse trabalho disponibiliza para a literatura dados relevantes acerca da determinação da qualidade do leite a partir de métodos quimiométricos. Nesse sentido, este estudo busca avaliar os parâmetros de qualidade do leite cru refrigerado produzido em diferentes unidades produtoras das microrregiões do Curimataú e Brejo Paraibano e investigar a relação entre as amostras através da aplicação da análise de PCA.

\section{MÉTODOS}

\section{Amostragem}

As amostras de leite cru refrigerado foram coletadas em tanques de expansão de dez unidades produtoras de leite (UPL) localizadas em cinco cidades da microrregião do Curimataú e Brejo Paraibano (Figura 1).

Figura 1. Localização geográfica das regiões de pontos de coleta de amostras de leite cru refrigerado em regiões do Brejo e Curimataú Paraibano.

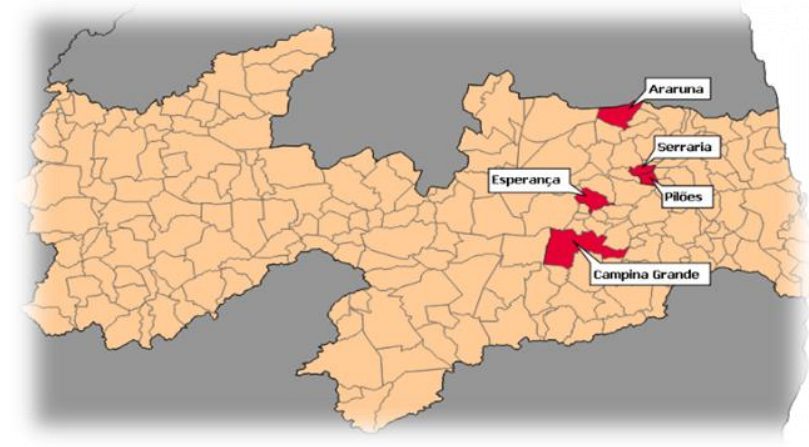

Fonte: próprio autor

Foram coletadas três amostras diferentes em cada unidade produtora, totalizando $\mathrm{n}=30$. Todas as análises foram realizadas em triplicata e os resultados expressos pela média das repetições e seu desvio padrão. As amostras foram distribuídas e codificadas conforme exibe a Tabela 1 .
Tabela 1 - Distribuição e descrição do número de amostras que foram analisadas

\begin{tabular}{cccc}
\hline $\begin{array}{c}\text { Tipo de } \\
\text { amostra }\end{array}$ & Cidade & $\begin{array}{c}\text { no de } \\
\text { UPL }\end{array}$ & Código \\
\hline & Araruna & 2 & A1-A2 \\
Leite cru & Pilões & 2 & P1-P2 \\
refrigerado & Serraria & 3 & S1-S2- \\
& Esperança & 2 & E1-E2 \\
& Campina & 1 & CG1 \\
& Grande & & \\
\hline & $\mathrm{n}=30$ & & \\
& & & \\
\hline
\end{tabular}

$\overline{\mathrm{UPL}}=$ unidade produtora de leite (cooperativa onde o leite foi produzido e coletado).

\section{Análise físico-química}

Todos os métodos físico-químicos utilizados na execução das análises seguiram as descrições do Instituto Adolfo Lutz ${ }^{[14]}$. As amostras de leite cru refrigerado foram avaliadas quanto aos parâmetros de acidez, crioscopia, densidade, gordura, extrato seco total (EST), extrato seco desengordurado (ESD) e potencial hidrogeniônico ( $\mathrm{pH})$. A acidez foi medida em acidímetro com solução Dornic e expressa em $\left({ }^{\circ} \mathrm{D}\right)$. Os valores do índice crioscopio $\left({ }^{\circ} \mathrm{H}\right)$ foram medidos no crioscopio eletrônico modelo - MK540 Flex bancada. A densidade relativa $(\mathrm{g} / \mathrm{mL})$ foi realizada por termolacto-densímetro de Quevenne, com escala entre 1,015 a $1,040{\mathrm{~g} . \mathrm{cm}^{-3}}^{-3}$ e corrigida a 15 ${ }^{\circ} \mathrm{C}$. A gordura (g/100 g) pelo método de Gerber. EST $(\mathrm{g} / 100 \mathrm{~g})$ foi realizado em estufa modelo - CAP-EC81 a $102{ }^{\circ} \mathrm{C}$, até peso constante. O ESD foi calculado pela diferença entre o teor do EST da amostra e seu respectivo teor de gordura (Equação 1). $\mathrm{O}$ pH foi medido em medidor de $\mathrm{pH}$ de bancada - modelo STARTER 2100. Também foi realizado o teste de redução do azul de metileno (TRAM), seguindo a metodologia proposta por Behmer[15] a leitura foi realizada a cada 30 minutos até que $4 / 5$ do tubo estivesse descorado.

$$
\operatorname{ESD}(\%)=\operatorname{EST}(\%)-\text { Gordura (\%) Equação } 1 .
$$




\section{Análises microbiológicas}

Para avaliar a qualidade microbiológica, as amostras foram refrigeradas a temperatura de $\pm 3{ }^{\circ} \mathrm{C}$ e acondicionadas em frascos estéreis de polietileno. Em seguida, foram transportadas e analisadas seguindo os métodos oficiais estabelecidos pela Instrução Normativa no 62/2003 do Ministério da Agricultura, Pecuária e Abastecimento - MAPA[16] para determinar a contagem de bactérias totais (CBT) e para a contagem de células somáticas (CCS) foi utilizada a metodologia proposta por Viana et a ${ }^{17]}$.

A CCS foi efetuada utilizando $2 \mathrm{~mL}$ de reagente no tubo e em seguida, foi adicionado $2 \mathrm{~mL}$ de leite com auxílio de uma pipeta, a mistura foi homogeneizada por 30 vezes durante 20 segundos. O tubo foi invertido, deixando o líquido escoar por 30 segundos, retornando-o para sua posição normal, e após 5 segundos foi feita a leitura. Os resultados obtidos foram expressos em CCS $/ \mathrm{mL}$. A contagem de bactérias totais (CBT) foi realizada utilizando o ágar para contagem (PCA) e após a incubação, à $37^{\circ} \mathrm{C}$ por 24 a 48 horas, os resultados foram expressos em unidade formadora de colônia por mililitro (UFC/mL). Para o cálculo de CBT foi utilizado um contador de colônias digital, em placas com mais de 25 colônias.

\section{Análise dos dados}

Os dados de composição físico-química e microbiológica foram submetidos à análise de variância (ANOVA - um fator) e as variáveis que apresentaram diferença significativa foram comparadas pelo teste de Tukey a $5 \%$ de significância e também foi calculado o coeficiente de correlação linear de Person. A PCA foi aplicada para avaliar o grau de similaridade entre as amostras a partir do conjunto total de dados disponíveis e foi calculado usando a matriz de correlação. As análises estatísticas foram executadas utilizando o programa estatístico Statistica v. 10.

\section{RESULTADOS E DISCUSSÃO}

\section{Análise físico-química}

Os resultados das análises físico-químicas nas amostras de leite cru refrigerado estão dispostos na Tabela 2.

Tabela 2 - Resultados das análises físico-químicas realizadas nas amostras de leite cru refrigerado, produzidos em diferentes propriedades rurais

\begin{tabular}{lccccccc}
\hline Amostras & $\begin{array}{c}\text { Gordura } \\
(\mathrm{g} / 100 \mathrm{~g})\end{array}$ & $\begin{array}{c}\text { EST } \\
(\mathrm{g} / 100 \mathrm{~g})\end{array}$ & $\begin{array}{c}\text { ESD } \\
(\mathrm{g} / 100 \mathrm{~g})\end{array}$ & $\begin{array}{c}\text { Densidade } \\
(\mathrm{g} / \mathrm{mL})\end{array}$ & $\begin{array}{c}\text { Acidez } \\
\left({ }^{\circ} \mathrm{D}\right)\end{array}$ & $\mathrm{pH}$ & ${\text { Crioscopia }\left({ }^{\circ} \mathrm{H}\right)}$ \\
\hline A1 & $4,07 \pm 0,12^{\mathrm{abd}}$ & $12,31 \pm 0,01^{\mathrm{bc}}$ & $8,35 \pm 0,05^{\mathrm{cd}}$ & $1,029 \pm 0,00^{\mathrm{ab}}$ & $15,17 \pm 0,29^{\mathrm{ab}}$ & $6,80 \pm 0,01^{\mathrm{a}}$ & $-0,538 \pm 0,00^{\mathrm{aef}}$ \\
A2 & $3,87 \pm 0,06^{\mathrm{acd}}$ & $11,94 \pm 0,21^{\mathrm{ab}}$ & $8,03 \pm 0,02^{\mathrm{a}}$ & $1,028 \pm 0,00^{\mathrm{ab}}$ & $15,13 \pm 0,32^{\mathrm{ab}}$ & $6,79 \pm 0,02^{\mathrm{a}}$ & $-0,541 \pm 0,00^{\mathrm{abc}}$ \\
P1 & $3,83 \pm 0,12^{\mathrm{ac}}$ & $12,42 \pm 0,27^{\mathrm{c}}$ & $8,05 \pm 0,02^{\mathrm{a}}$ & $1,028 \pm 0,00^{\mathrm{ab}}$ & $15,80 \pm 0,29^{\mathrm{ab}}$ & $6,63 \pm 0,15^{\mathrm{a}}$ & $0,539 \pm 0,00^{\mathrm{abf}}$ \\
P2 & $4,07 \pm 0,11^{\mathrm{abd}}$ & $12,38 \pm 0,08^{\mathrm{c}}$ & $8,03 \pm 0,02^{\mathrm{a}}$ & $1,029 \pm 0,00^{\mathrm{ab}}$ & $14,70 \pm 0,58^{\mathrm{b}}$ & $6,80 \pm 0,10^{\mathrm{a}}$ & $-0,540 \pm 0,00^{\mathrm{ab}}$ \\
S1 & $3,83 \pm 0,06^{\mathrm{ac}}$ & $11,95 \pm 0,21^{\mathrm{ab}}$ & $8,19 \pm 0,15^{\mathrm{ac}}$ & $1,027 \pm 0,00^{\mathrm{a}}$ & $16,00 \pm 0,00^{\mathrm{a}}$ & $6,77 \pm 0,01^{\mathrm{a}}$ & $-0,535 \pm 0,00^{\mathrm{def}}$ \\
S2 & $4,13 \pm 0,15^{\mathrm{bd}}$ & $12,89 \pm 0,04^{\mathrm{d}}$ & $8,58 \pm 0,04^{\mathrm{be}}$ & $1,029 \pm 0,00^{\mathrm{ab}}$ & $16,30 \pm 0,58^{\mathrm{a}}$ & $6,79 \pm 0,01^{\mathrm{a}}$ & $-0,545 \pm 0,00^{\mathrm{c}}$ \\
S3 & $3,27 \pm 0,06^{\mathrm{e}}$ & $11,43 \pm 0,03^{\mathrm{c}}$ & $8,41 \pm 0,01^{\mathrm{de}}$ & $1,028 \pm 0,00^{\mathrm{ab}}$ & $15,33 \pm 0,58^{\mathrm{ab}}$ & $6,67 \pm 0,02^{\mathrm{a}}$ & $-0,534 \pm 0,00^{\mathrm{de}}$ \\
E1 & $4,27 \pm 0,06^{\mathrm{b}}$ & $12,91 \pm 0,01^{\mathrm{d}}$ & $8,61 \pm 0,01^{\mathrm{b}}$ & $1,030 \pm 0,00^{\mathrm{b}}$ & $16,20 \pm 0,29^{\mathrm{a}}$ & $6,79 \pm 0,01^{\mathrm{a}}$ & $-0,543 \pm 0,00^{\mathrm{bc}}$ \\
E2 & $4,17 \pm 0,06^{\mathrm{b}}$ & $12,91 \pm 0,03^{\mathrm{d}}$ & $8,61 \pm 0,01^{\mathrm{b}}$ & $1,029 \pm 0,00^{\mathrm{ab}}$ & $15,20 \pm 0,29^{\mathrm{ab}}$ & $6,79 \pm 0,01^{\mathrm{a}}$ & $-0,541 \pm 0,00^{\mathrm{abc}}$ \\
CG1 & $3,67 \pm 0,15^{\mathrm{c}}$ & $11,64 \pm 0,13^{\mathrm{ac}}$ & $8,12 \pm 0,08^{\mathrm{a}}$ & $1,029 \pm 0,00^{\mathrm{ab}}$ & $14,70 \pm 0,58^{\mathrm{b}}$ & $6,65 \pm 0,01^{\mathrm{a}}$ & $-0,532 \pm 0,00^{\mathrm{d}}$ \\
\hline
\end{tabular}

*Médias seguidas de letras diferentes na mesma coluna representam diferença significativa entre si pelo teste de Tukey $(p<0,05)$.

Com relação ao teor de gordura, foi observada diferença significativa $(p<0,05)$ entre A1, S3 e CG1. De acordo com a IN $n^{\mathbf{0}} 76^{[4]}$ o teor mínimo de gordura é de 3,0 g/100 g e todas as amostras estão acima do valor estabelecido na IN no 76 . Estando esses valores em concordância com os encontrados por Bastos et 
al. ${ }^{18]}$ que ao analisar 87 amostras de leite, determinaram teores de gordura superiores a 3,0 g/100 g. De acordo com Belli et al. ${ }^{[19]}$ o teor de gordura é um dos componentes do leite mais passiveis de apresentar variação, e pode ser influenciado por diversos fatores. Angicano et al. ${ }^{20]}$ destacam que o teor de gordura abaixo do estabelecido na IN no ${ }^{-}$76, pode ocorrer em função das práticas de adulteração realizadas no leite. Segundo Calderón et al.[21] as fibras presentes na alimentação do animal, também influenciam no teor de gordura, devido à quantidade de ácidos graxos produzidos no rúmen[22].

O teor de EST corresponde a todos os componentes do leite, exceto a água. Entre eles, os mais relevantes são o teor de gordura e proteína, que afeta diretamente o rendimento dos produtos lácteos e, portanto, são de grande interesse para a indústria [23]. Os valores médios de EST variaram entre 11,43 e $12,91 \mathrm{~g} / 100 \mathrm{~g}$. Todas as amostras apresentaram valores acima do limite mínimo estabelecido pela legislação de 11,4 g/100 g. Esses resultados podem estar relacionados com alguns fatores como condições climáticas, do solo, da saúde e genética do rebanho, do estágio de lactação, da idade do animal e dieta que influenciaram positivamente para obtenção dos resultados ${ }^{[18]}$.

Os valores médios de ESD variaram entre 8,03 e 8,61 g/100 g e de acordo com a IN no 76, o valor mínimo é de 8,4 g/100 $\mathrm{g}\left[{ }^{[4]}\right.$. Vargas et al.[24] ao avaliar a qualidade de leite cru encontraram valores de ESD variando entre 8,35 e $8,47 \mathrm{~g} / 100 \mathrm{~g}$. Os autores atribuíram essa variação ao aumento da CCS. Bastos et al. ${ }^{[18]}$ discutem a relação entre o teor de ESD e a densidade, e verificaram uma correlação diretamente proporcional. No entanto no presente estudo, esses dados não estavam correlacionados $(p>0,05)$. Foi observado que os valores de densidade relativa situaram-se entre 1,027 e $1,030 \mathrm{~g} / \mathrm{mL}$ e apenas a amostra S1 $(1,027 \mathrm{~g} / \mathrm{mL})$ apresentou diferença significativa $(\not<0,05)$ em relação a E1 $(1,030 \mathrm{~g} / \mathrm{mL})$. Além disso, S1 está abaixo do preconizado na legislação $(1,028$ a $1,034 \mathrm{~g} / \mathrm{mL})$. Essa redução pode esta atribuída a fraude por aguagem ou desnate. Segundo Mareze et al.[25] a densidade pode identificar adulteração do leite com água somente acima de 10 $\%$, no teor de gordura acima de $12 \%$ e no ESD, acima de $4 \%$, caso a adição de água for acompanhada de reconstituintes como o sal, amido ou açúcar e for realizada de forma equilibrada, a prova de densidade pode não ser capaz de detectá-la.
Em relação aos resultados de acidez, os valores médios observados diferiram significativamente $(p<$ $0,05)$ e foram de 14,70 e $16,30^{\circ} \mathrm{D}$, onde todas estavam dentro do padrão $\left(14,00-18,00{ }^{\circ} \mathrm{D}\right)$. A análise de acidez tem por finalidade verificar a qualidade do leite cru, fundamentando-se no ponto de viragem da fenolftaleína (indicador ácido base), que é influenciado pelo teor de ácido láctico na matériaprima, o qual é produto da fermentação da lactose por bactérias láticas presentes no leite. Valores abaixo do indicado na legislação podem ser influenciados pela fermentação da lactose, indicando assim a presença de alta carga microbiana, aumentando o conteúdo de acidez, enquanto teores muito baixos são indicativos de fraude pelo uso de conservadores, como, por exemplo, bicarbonato e citrato de sódio[26].

Os valores médios de $\mathrm{pH}$ foram de 6,63 a 6,80 e não apresentaram diferença significativa $(\phi>0,05)$, considerando o intervalo aceitável de 6,60 a 6,80 para o leite produzido no Brasil[27], todas as amostras apresentaram $\mathrm{pH}$ dentro do intervalo. $\mathrm{O} \mathrm{pH}$ verifica a quantidade de íons de hidrogênio $\left(\mathrm{H}^{+}\right)$que existe em uma determinada amostra, quanto mais $\mathrm{H}^{+}$, mais baixo o pH e mais ácido ele será[28]. De acordo com Tronco ${ }^{[23]}$ os fatores que contribuem para alteração do $\mathrm{pH}$ são: a produção de ácido lático por microrganismos, inflamação nas glândulas mamárias e fraudes por adição de neutralizantes.

Segundo Paula et al. ${ }^{[2]}$ o índice crioscópico é a medida do ponto de congelamento do leite ou da depressão do ponto de congelamento do leite em relação ao da água. Em relação ao ponto de congelamento do leite, foi observado que os resultados apresentaram diferença significativa $(\phi<$ $0,05)$ e os dados encontrados para esse parâmetro variaram de $-0,532{ }^{\circ} \mathrm{He}$ e $-0,545^{\circ} \mathrm{H}$. Todas as amostras atendem aos limites estabelecidos pela legislação ($0,530{ }^{\circ} \mathrm{H}$ a $\left.-0,555^{\circ} \mathrm{H}\right)$, valores mais próximos do ponto de congelamento da água, indica a presença de água no leite[4]. De acordo com Mareze et al. ${ }^{[25]} \mathrm{com}$ apenas $1 \%$ de adição de água, já altera o índice crioscópico do leite. Os autores ao investigar a adição de adulterantes em leite pasteurizado por meio de provas oficiais, encontraram valores médios de $-0,537$ ${ }^{\circ} \mathrm{H} \mathrm{e}-0,549^{\circ} \mathrm{H}$, indicando que as amostras analisadas possivelmente não foram adulteradas. 
A Tabela 3 dispõe dos resultados do tempo de viragem ao azul de metileno, em minutos, para cada amostra analisada.

Tabela 3 - Valores médios do tempo de reação do azul de metileno em amostras de leite cru refrigerado

\begin{tabular}{cc}
\hline Amostras & TRAM (minutos) \\
\hline A1 & $241 \pm 4,04^{\mathrm{ab}}$ \\
A2 & $298 \pm 2,65^{\mathrm{c}}$ \\
P1 & $220 \pm 2,00^{\mathrm{g}}$ \\
P2 & $198 \pm 2,31^{\mathrm{f}}$ \\
S1 & $171 \pm 3,06^{\mathrm{e}}$ \\
S2 & $312 \pm 2,52^{\mathrm{h}}$ \\
S3 & $249 \pm 3,21^{\mathrm{b}}$ \\
E1 & $292 \pm 3,06^{\mathrm{c}}$ \\
E2 & $237 \pm 4,93^{\mathrm{a}}$ \\
CG1 & $156 \pm 3,06^{\mathrm{d}}$ \\
\hline
\end{tabular}

*TR $\overline{\mathrm{AM}}=$ Tempo de reação do azul de metileno.

Com relação aos resultados de TRAM, foi possível observar diferença significativa entre as amostras $(p<0,05)$. Esse teste mede indiretamente a população bacteriana no leite, dessa forma, quanto mais insatisfatórias forem às condições de manejo, mais rapidamente ocorrerá a redução do corante (azul de metileno) a um composto incolor ${ }^{[30]}$. As amostras A1, A2, S2, S3 e E1 demonstraram coloração após 4 horas, onde o limite mínimo foi para a amostra CG1 (156 min ou 2,6 horas) e o máximo, para a amostra S2 (312 min ou 5,2 horas). A legislação vigente não estabelece limite para esse parâmetro. Mendonça et al.[31] ao avaliarem a qualidade do leite cru refrigerado comercializado informalmente no Norte do Paraná identificaram que o tempo mínimo de redução do corante é de 90 minutos. Os autores observaram que $35 \%$ das amostras estudadas demoraram mais de 5 horas para reduzir o corante.

\section{Análise microbiológica}

A Tabela 4 exibe os resultados das análises de CCS e CBT nas amostras de leite cru refrigerado.
Tabela 4 - Valores médios de CCS e CBT do leite cru refrigerado obtido em diferentes propriedades rurais

\begin{tabular}{ccc}
\hline Amostras & $\begin{array}{c}\text { CCS } \\
\text { (Mil } \\
\text { células/mL) }\end{array}$ & $\begin{array}{c}\text { CBT } \\
\text { (UFC/mL) }\end{array}$ \\
\hline A1 & $310 \pm 17,3^{\mathrm{c}}$ & $1830 \pm 0,04^{\mathrm{a}}$ \\
A2 & $313 \pm 10,4^{\mathrm{c}}$ & $2003 \pm 0,00^{\mathrm{ab}}$ \\
P1 & $408 \pm 2,89^{\mathrm{a}}$ & $4071 \pm 0,06^{\mathrm{d}}$ \\
P2 & $396 \pm 6,08^{\mathrm{ad}}$ & $3006 \pm 0,00^{\mathrm{c}}$ \\
S1 & $405 \pm 4,04^{\mathrm{a}}$ & $2967 \pm 0,05^{\mathrm{c}}$ \\
S2 & $214 \pm 6,03^{\mathrm{b}}$ & $1769 \pm 0,23^{\mathrm{a}}$ \\
S3 & $372 \pm 2,52^{\mathrm{d}}$ & $2222 \pm 0,18^{\mathrm{b}}$ \\
E1 & $231 \pm 3,21^{\mathrm{a}}$ & $1116 \pm 0,02^{\mathrm{e}}$ \\
E2 & $343 \pm 16,0^{\mathrm{e}}$ & $4111 \pm 0,12^{\mathrm{d}}$ \\
CG1 & $404 \pm 4,58^{\mathrm{a}}$ & $19361 \pm 0,05^{\mathrm{ab}}$ \\
\hline
\end{tabular}

*Médias seguidas de letras diferentes na mesma coluna representam diferença significativa entre si pelo teste de Tukey $(p<0,05)$. CCS $=$ Contagem de células somáticas; $\mathrm{CBT}=$ Contagem bacteriana total.

Para os resultados de CCS, as amostras apresentaram diferença significativa $(p<0,05)$ e possuem contagens que variaram entre 214.333 células $/ \mathrm{mL}$ e 408.333 células $/ \mathrm{mL}$. A Instrução Normativa $n^{-}$- 76, estabelece um limite de tolerância para CCS de no máximo 500.000 mil células $/ \mathrm{mL}$, portanto, todas a amostras estão de acordo com o que a legislação preconiza. Vargas et al.[24] observaram que amostras de leite que apresentam valores elevados de CCS pode estar correlacionada com os efeitos decorrentes da mastite subclínica. Van Schaik et al. [32] identificaram que quanto maior a incidência da mastite no rebanho, maior será o aumento de resíduos de antibióticos no leite e isso se deve ao fato de não ser respeitado o período de carência dos antibióticos que são aplicados durante o tratamento da inflamação nas glândulas. Quintão et al.[33] ao avaliarem a qualidade de leite cru refrigerado, apresentou CCS superiores a 500.000 mil células $/ \mathrm{mL}$ e verificaram que de 6,8 a $25 \%$ de suas amostras estavam acima do 
limite permitido pela legislação. Valores elevados de CCS no leite influenciam na produção, na qualidade e no rendimento dos produtos lácteos ${ }^{[34]}$.

As amostras apresentaram diferença significativa $(\phi<0,05)$ em CBT, variando entre 1116 e 19361 $\mathrm{UFC} / \mathrm{mL}$, respectivamente. Todas as amostras analisadas estão de acordo com que a IN $\mathrm{n}^{\circ} 76$ estabelece (limite de $300.000 \mathrm{UFC} / \mathrm{mL}$ para CBT). Oliveira et al. ${ }^{[35]}$ ao analisarem 11.523 amostras de leite cru refrigerado coletadas no município de Vassouras - RJ, determinaram valores de $3700 \mathrm{UFC} / \mathrm{mL}$. Os autores justificam as baixas contagens encontradas ao fato de que as coletas das amostras ocorreram logo após a ordenha, antes que o leite tenha contato com algum contaminante biológico. Lampugnani et al. ${ }^{[36]}$ ao analisarem amostras de leite cru determinaram contagens muito elevadas $980000 \mathrm{UFC} / \mathrm{mL}$, estando esses resultados relacionados a ausência de higienização no momento da ordenha.

\section{Análise quimiométrica}

Para obter uma visão geral da qualidade das amostras de leite cru refrigerado produzido em diferentes UPLs, os gráficos de PCA foram criados com base no conteúdo dos seguintes parâmetros: gordura, EST, ESD, Densidade, Acidez, pH, crioscopia, TRAM, CCS e CBT. As Figuras 2 e 3 ilustram os resultados de scores dos primeiros componentes principais, PC1 e PC2, que explicaram respectivamente $54,03 \%$ e $15,39 \%$ e demonstraram a variância armazenada em cada componente principal expressa pelos autovalores da matriz padronizada.

Figura 2. Scores da PCA em diferentes amostras de leite cru refrigerado

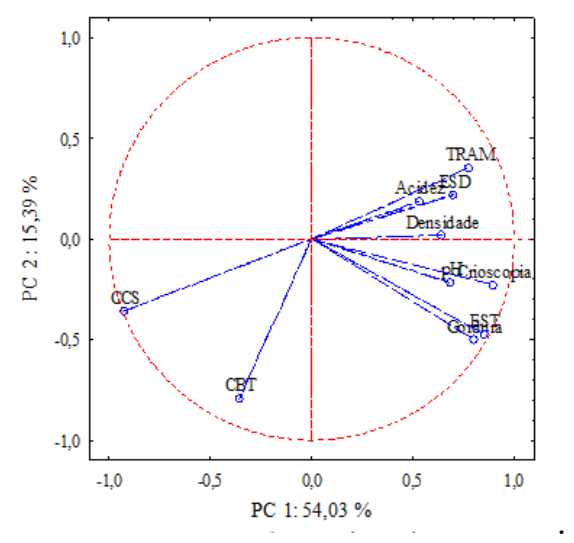

Figura 3. Carga fatorial da PCA em diferentes

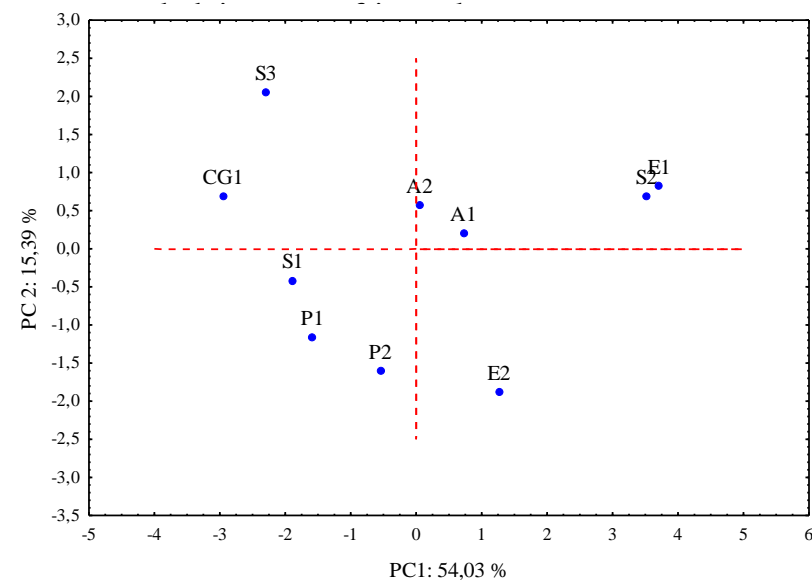

A partir dos resultados obtidos com a PCA, foi possível observar que os dois primeiros componentes principais PC1 e PC2 conseguiram explicar 69,42\% da variância observada entre o conjunto de dados. As Figuras 2 e 3, mostram a separação das amostras e as variáveis mais importantes nessa separação.

As diferentes amostras de leite cru refrigerado coletadas em dez UPLs foram separadas em cinco grupos, o grupo (I) foi separado pelas amostras A2 e A1, localizadas no centro do gráfico, indicando que não foram influenciadas por nenhum vetor, grupo (II) foi constituído pelas amostras S1, P1 e P2 caracterizado principalmente pelos vetores de CCS e CBT, sugerindo que essas amostras possivelmente estão mais correlacionadas entre si e possuem contagens de CCS e CBT muito similares. Grupo (III) formado pela amostra E2, caracterizada principalmente pelos vetores de EST e gordura, sugere que possivelmente essa amostra apresenta altos teores desses parâmetros. As amostras S2 e E1 constituem o grupo (IV) que foi descrito pelos vetores de densidade, TRAM, ESD e acidez, sugerindo assim que as mesmas estão mais correlacionadas, sendo mais similares em função desses parâmetros e provavelmente apresentam altos valores. O (V) é caracterizado pelas amostras CG1 e S3. A amostra S3 se relaciona de maneira inversamente proporcional aos vetores de EST e gordura, enquanto a amostra CG1 com os vetores de $\mathrm{pH}$ e crioscopia, sugerindo que essas amostras possuem teores menores desses 
parâmetros, confirmando assim os dados encontrados pela ANOVA apresentados na (Tabela 2).

Logo, a partir das correlações dos componentes principais com os vetores, pode-se inferir que o PC1 (eixo $\mathrm{x}$ ) está mais associado aos vetores de TRAM, ESD, acidez, densidade, $\mathrm{pH}$, crioscopia, EST, gordura e CCS, enquanto CBT está mais associado ao PC2 (eixo y).

\section{Coeficiente de correlação de Pearson}

A Tabela 5 ilustra as correlações encontradas entre as variáveis físico-químicas e microbiológicas do leite cru refrigerado produzido em diferentes unidades produtoras.

Tabela 5 - Matriz de correlação de Pearson entre as variáveis estudadas

\begin{tabular}{|c|c|c|c|c|c|c|c|c|c|c|}
\hline & Gordura & $\overline{E S T}$ & ESD & Densi. & Acidez & $\mathrm{pH}$ & Criosc. & CCS & CBT & TRAM \\
\hline Gordura & 1,000 & 0,893* & $\begin{array}{l}-0,556^{*} \\
\end{array}$ & $0,666^{*}$ & 0,204 & 0,137 & 0,781* & $-0,627^{*}$ & $-0,248$ & 0,356 \\
\hline EST & $0,893 *$ & 1,000 & $-0,578^{*}$ & $0,552 *$ & 0,044 & 0,195 & $-0,800 *$ & $-0,538^{*}$ & $-0,053$ & 0,346 \\
\hline ESD & $-0,556^{*}$ & $-0,578^{*}$ & 1,000 & $0,472 *$ & 0,060 & 0,182 & 0,357 & $-0,629 *$ & $-0,347$ & 0,320 \\
\hline Densi. & $0,666^{*}$ & $0,552 *$ & 0,172 & 1,000 & $-0,014$ & 0,278 & $0,516^{*}$ & $-0,334$ & $-0,245$ & 0,155 \\
\hline Acidez & 0,204 & 0,144 & 0,060 & $-0,014$ & 1,000 & $-0,780^{*}$ & 0,277 & $-0,175$ & $-0,200$ & $-0,791 *$ \\
\hline $\mathrm{pH}$ & 0,237 & 0,095 & 0,182 & 0,278 & $-0,511 *$ & 1,000 & 0,080 & 0,209 & $-0,202$ & 0,299 \\
\hline Criosc. & $0,781 *$ & $-0,800 *$ & 0,357 & $0,516^{*}$ & 0,277 & 0,019 & 1,000 & $-0,022$ & $-0,188$ & 0,298 \\
\hline CCS & $-0,627^{*}$ & $-0,538^{*}$ & $-0,629 *$ & $-0,334$ & $-0,175$ & 0,177 & $-0,122$ & 1,000 & $0,859 *$ & $0,838^{*}$ \\
\hline CBT & $-0,248$ & $-0,053$ & $-0,347$ & $-0,245$ & $-0,200$ & $-0,202$ & $-0,188$ & $0,703 *$ & 1,000 & $-0,536^{*}$ \\
\hline TRAM & 0,356 & 0,346 & 0,358 & 0,155 & $-0,791 *$ & 0,298 & 0,018 & $0,766 *$ & $-0,506^{*}$ & 1,000 \\
\hline
\end{tabular}

*Correlação significativa $(p<0,05)$.

Constataram-se correlações positivas e negativas (à medida que uma aumenta, a outra sempre diminui) entre os parâmetros de qualidade físico-química e microbiológica das amostras de leite cru refrigerado.

Para os parâmetros de gordura e EST existe uma correlação positiva muito forte $(r=0,893)$, evidenciando que o aumento ou redução entre ambos é proporcional. No entanto, essa relação já era esperada, tendo em vista que a gordura é um dos principais constituintes que compõem o EST. Enquanto ESD e gordura mostraram uma correlação negativa moderada $(r=-0,556)$, o que era esperado, já que o ESD compreende todos os constituintes do leite, exceto a água e a gordura. A densidade relativa também apresentou uma correlação positiva moderada $(r=0,666)$ com o teor de gordura indicando que provavelmente $66,6 \%$ dos teores de densidade e gordura aumentam ou reduzem proporcionalmente. Entre o teor de gordura e crioscopia foi encontrado uma correlação positiva forte $(r=0,781)$. A crioscopia apresentou correlação negativa forte com $\operatorname{EST}(r=-0,800)$, e correlação positiva moderada com densidade $(r=0,516)$.

Para os teores de $\mathrm{pH}$ e acidez foi encontrada uma correlação negativa forte $(r=-0,780)$, o que sugere que $78,0 \%$ da redução do $\mathrm{pH}$ ocorrem proporcionalmente com o aumento do teor de acidez. A CCS correlacionou negativamente com gordura $(r$ $=-0,627)$, EST $(r=-0,538)$ e ESD $(\mathrm{r}=-0,629)$, no entanto ambas correlações são moderadas. Eckstein $e t$ al.[30] observaram que esses constituintes são diretamente afetados por fatores como elevada CCS e CBT, o que não foi observado nesse estudo.

Foi observada correlação negativa moderada entre CBT e TRAM com $(r=-0,506)$, visto que a medida que 50,6\% da CBT aumenta, mais rápido o ocorre a redução do corante. E também foi visto uma 
correlação positiva forte entre CBT e CCS $(r=0,859)$, no entanto Vargas et al. ${ }^{[24]}$ verificaram correlação fraca $(r=0,330)$ entre essas variáveis. Este resultado evidencia os diferentes comportamentos do úbere diante dos agentes causadores da mastite subclínica, ou microbiota residente. O TRAM apresentou uma correlação positiva forte com CCS $(r=0,838)$ e correlação negativa forte com acidez $(r=-0,791)$, respectivamente. Evidenciando que o TRAM é um teste efetivo para avaliar o nível de contaminação do leite cru refrigerado.

\section{CONCLUSÃO}

A partir dos resultados da composição físicoquímica foi possível identificar que, no geral, as amostras apresentaram-se de boa qualidade, uma vez que atendiam os limites estabelecidos pela legislação, com exceção de A1, A2, P1, P2, S1 e CG1 para o teor de ESD e S1 para o parâmetro de densidade, que estavam abaixo do limite mínimo permitido. Com relação aos parâmetros microbiológicos, os resultados demonstraram que as amostras atendiam os limites preconizados na legislação vigente.

Os resultados obtidos a partir da análise multivariada são de grande relevância porque possibilitou a separação das amostras em cinco grupos, a partir da análise conjunta dos descritores estudados. Além disso, a análise de PCA indicou os descritores responsáveis pelo agrupamento, das dez amostras estudas. Foi visto que as amostras que compõem os grupos (III) e (IV) apresentaram forte correlação com os vetores de TRAM, ESD, acidez, densidade, $\mathrm{pH}$, crioscopia, EST e gordura, demonstrando que essas amostras provavelmente possuem teores mais altos e que apresentam melhor padrão de qualidade em ralação as demais. As amostras que formam o grupo (V) se correlacionaram inversamente com esses vetores e a menor proporção dos vetores de $\mathrm{pH}$, crioscopia, EST e gordura, classificaram essas amostras como de qualidade inferior.

\section{REFERÊNCIAS}

[1] Dias V, et al. Métodos oficiais empregados para autenticidade, controle da qualidade e detecção de fraudes em leite cru refrigerado no Brasil. Brazilian Journal of Development. 2020; 6:7129-7137.
[2] Andrade K, et al. Qualidade do leite bovino nas diferentes estações do ano no estado do Rio Grande do Norte. Revista Brasileira de Ciência Veterinária. 2014; 21:213-216.

[3] BRASIL, Ministério da Agricultura, Pecuária e Abastecimento. Decreto no 9.013, 29 de março de 2017. Regulamento da Inspeção Industrial e Sanitária de Produtos de Origem Animal. Diário Oficial da República Federativa do Brasil. 2017 jun 01; 3.

[4] BRASIL, Ministério da Agricultura, Pecuária e Abastecimento. Instrução Normativa no 76, de 26 de novembro de 2018. Regulamento Técnico de Identidade e Qualidade de Leite Cru Refrigerado, Regulamento Técnico de Identidade e Qualidade de Leite Pasteurizado e o Regulamento Técnico de Identidade e Qualidade de Leite Pasteurizado Tipo A. Diário Oficial da União. 2018 nov 30; 01.

[5] Alves MP, Dantas TNP, Gusmão TAS. Avaliação da qualidade de leite produzido no município de Caturité. Revista Brasileira de Gestão Ambiental. 2020; 14:17-27.

[6] Neves R, et al. Avaliação sazonal e temporal da qualidade do leite cru goiano tendo como parâmetros a contagem celular somática e a contagem bacteriana total. Archives of Veterinary Science. 2019; 24:10-23.

[7] Queiroz R, et al. Contagem bacteriana total do leite cru refrigerado em função do período do ano. PUBVET. 2019; 13:1-5.

[8] Gonçalves R, et al. Microbiological, cellular, physical and chemical characteristics of refrigerated raw milk in Aparecida do Taboado-MS. Brazilian Journal of Development. 2020; 6:7290-7300.

[9] Leite A, Mendonça M, Mendonça K, Franque M. Causas de não recebimento do leite cru refrigerado em usina de beneficiamento do Agreste Meridional de Pernambuco. Revista do Instituto de Laticínios Cândido Tostes. 2019; 74:86-95.

[10] Strani L, et al. Milk renneting: Study of process factor influences by FT-NIR spectroscopy and chemometrics. Food and Bioprocess Technology. 2019; 12:954-963.

[11] Ferreira M. Quimiometria: Conceitos, métodos e aplicações. Campinas: UNICAMP; 2015.

[12] Brereton R. Chemometrics: data analysis for the laboratory and chemical plant. Chichester: John Wiley \& Sons Ltd; 2003.

[13] Silva J, et al. Rapadura de caldo de cana pura e com adição de açúcar refinado: Análise físico-química e 
Quimiometria na classificação de leite cru refrigerado. Melo et al.

classificação por espectroscopia NIRR e quimiometria. Revista Virtual de Química. 2019; 11:1318-1329.

[14] Instituto Adolfo Lutz. Normas Analíticas do Instituto Adolfo Lutz. Métodos químicos e físicos para análise de alimentos. São Paulo: IMESP; 2008.

[15] Behmer M. Tecnologia do leite: Produção, industrialização e análise. São Paulo: Nobel; 1976.

[16] BRASIL. Ministério da Agricultura, Pecuária e Abastecimento. Departamento de Inspeção de Produtos de Origem Animal. Instrução Normativa no. 62, de 26 de agosto de 2003. Métodos analíticos oficiais para análises microbiológicas para controle de produtos de origem animal e água. Diário Oficial da República Federativa do Brasil. Brasília, DF, 18 set. 2003.

[17] Viana B, et al. (2010). Avaliação da eficiência do SomaticellÂß para o diagnóstico da contagem indireta de células somáticas no leite de búfalas. Revista de Ciências Agrárias Amazonian Journal of Agricultural and Environmental Sciences. 2010; 53: 24-30.

[18] Bastos L, et al. Conformity of refrigerated raw milk from family production units of southern Espírito Santo. Ciência Animal Brasileira. 2018; 19:1-13.

[19] Belli C, et al. Qualidade do leite cru refrigerado obtido em unidades produtoras no sudoeste do Paraná. Revista de Ciências Agroveterinárias. 2016; 16:109-120.

[20] Angicano M, Braga A, Aroeira L, Rangel A, Silva M. Cattle milk quality in the Semiarid region of Rio Grande do Norte, Brazil. Semina: Ciências Agrárias. 2015; 36:28092818.

[21] Calderón A, García F, Martínez G. Indicadores de calidad de leches crudas en diferentes regiones de Colombia. Revista MVZ Córdoba. 2006; 11:725-737.

[22] González G, Sánchez B, Vázquez R. Calidad de la leche cruda. Primer Foro Sobre Ganadería Lechera de la Zona Alta de Vera cruz. 2010; 10.

[23] Tronco V. Manual para inspeção de qualidade do leite. Santa Maria: UFSM; 2010.

[24] VARGAS, DPD. et al. Correlações entre contagem de células somáticas e parâmetros físico-químicos e microbiológicos de qualidade do leite. Ciência Animal Brasileira. 2014; 15:473-483.

[25] Mareze J, et al. Detecção de adulterações do leite pasteurizado por meio de provas oficiais. Semina: Ciências Biológicas e da Saúde. 2015; 36:283-290.
[26] Oliveira K, Kobori C, Ubaldo J. Evaluation of physical-chemical quality, labeling and occurrence of adulterations in UHT milk samples. Revista do Instituto de Laticínios Cândido Tostes. 2019; 74:195-206.

[27] Santos M, Fonseca L. Estratégias para controle de mastite e melhoria da qualidade do leite. Barueri: Manole; 2007.

[28] Damodaran S, Parkin K. Química de alimentos de Fennema. Porto Alegre: Artmed; 2019.

[29] Paula F, Cardoso C, Rangel M. Análise físico-química do leite cru refrigerado proveniente das propriedades leiteiras da região sul fluminense. Revista Eletrônica TECCEN. 2010; 3:7-17.

[30] Eckstein I, et al. Qualidade do leite e sua correlação com técnicas de manejo de ordenha. Scientia Agraria Paranaensis. 2014; 13:143-151.

[31] de Mendonça C, et al. Qualidade Fisico-Química de Amostras de Leite Cru comercializadas Informalmente no Norte do Paraná. Journal of Health Sciences. 2009; 11:4.

[32] Van Schaik G, Lotem G, Schukken Y. Trends in somatic cell counts, bacterial counts, and antibiotic residue violations in New York State during. Journal Dairy Science. 2002; 85:782-789.

[33] Quintão L, et al. Evolution and factors influencing somatic cell count in raw milk from farms in Viçosa, state of Minas Gerais. Acta Scientiarium: Animal Sciences. 2017; 39:393-399.

[34] Sharma N, Singh N, Bhadwal M. Relationship of somatic cell count and mastitis: An overview. AsianAustralasian Journal of Animal Sciences. 2011; 24:429-438.

[35] Oliveira A, et al. Qualidade microbiológica de doces de leite comercializados no Sul de Minas Gerais. Revista do Instituto de Laticínios Cândido Tostes. 2012; 67:11-14.

[36] Lampugnani C, et al. Qualidade do leite cru refrigerado e características da produção leiteira na mesorregião oeste paranaense, Brasil. Revista do Instituto de Laticínios Cândido Tostes. 2018; 73:19-26. 